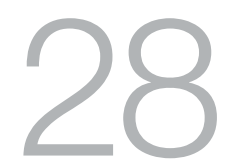

\title{
Local Tourist on a Bus Ride Home
}

\section{Audrey Brown-Pereira}

cool breeze sweeping sweet sweat of sadness

(through the cold hot air of the open closed window)

look 'sweet-e'

not with your i i dar-ling

? (anonymous object sits silently inside palm of her head)

the mist kisses the mountains

the mountains kiss the sky

coloured pockets of green \& gold \& blue

sing her a familiar song she thought she could never understand

(fault?)

tuatua maori

no

church

no

ura

kare?

echoed an even more familiar voice inside her head 2 herself the bird flies over the sun the sun flies in 2 the sea 
TOURING PACIFIC CULTURES

thoughts ( $\mathrm{r}$ ) / evolve as the km (s) clock from papa joe's watch \& the o-do-me-ter

of the yellow - yellow/jam packed/yellow/jam packed bus

(on the $1 / 2 \mathrm{hr}$ anti-clock-wise of course)

$\begin{array}{lllllll}10 & 9 & 8 & 7 & 6 & 5 & 4\end{array}$

watch the $\mathrm{c}$

through the trees

through the houses

through the stones that paint each stop with a story of a somebody and a somewhere that a someone(s) st il l loves

can u c?

as they pass herstory in arorangi \& tupapa

teuki C 
This text is taken from Touring Pacific Cultures, edited by Kalissa Alexeyeff and John Taylor, published 2016 by ANU Press, The Australian National University, Canberra, Australia. 